\title{
Trauma-induced endophthalmitis caused by Acinetobacter anitratus
}

\author{
DAVID B. MARK ${ }^{1}$ AND MICHAEL W. GAYNON ${ }^{2}$
}

From ${ }^{1}$ Massachusetts Eye and Ear Infirmary and Eye Research Institute of Retina Foundation, Boston, Massachusetts, and ${ }^{2}$ Stanford Medical Center, Stanford, California, USA

SUMMARY A 56-year-old man sustained an intraocular injury by a piece of steel followed by endophthalmitis, which resolved after lensectomy, vitrectomy, and intravitreal injections of gentamicin. Acinetobacter anitratus was the organism responsible for the endophthalmitis. It is a Gram-negative polymorphic organism that can resemble several other pathogens and possesses unpredictable antibiotic susceptibility. $A$. anitratus is an important cause of nosocomial infection but has not previously been reported as a cause of endophthalmitis following trauma.

Acinetobacter calcoaceticus is a ubiquitous organism. Formerly known as Mima, Herellea, and Bacterium anitratum, the organism may be mistaken for Neisseria or other Gram-negative pathogens. One of the subspecies, Acinetobacter lwoffi, has been reported twice to cause serious ocular infection. ${ }^{12}$ The other subspecies, Acinetobacter anitratus, has been mentioned once as a cause of a marginal corneal ulcer ${ }^{3}$ and as a cause of endophthalmitis after phacoemulsification. ${ }^{4}$ We now report the first case of trauma-induced endophthalmitis caused by Acinetobacter anitratus.

\section{Case report}

A 56-year-old black man was apparently well until he was struck in the right eye by a piece of steel when he was hammering an automobile driveshaft. He presented one day later with pain and loss of vision in the right eye (Fig. 1).

On examination visual acuity was light perception in the right eye and $6 / 6(20 / 20)$ in the left eye. The conjunctiva in the right eye was markedly injected, and there was a self-sealing entry site in the nasal cornea. A $15 \%$ hypopyon was present, and fibrin had nearly secluded the pupil. Applanation pressure was $35 \mathrm{mmHg}$ in the right eye and $14 \mathrm{mmHg}$ in the left. A cataractous lens prevented evaluation of the right fundus. The left eye was normal.

The patient's white blood cell count was $14.5 \times 10^{9} / 1$, with a shift to the left. $X$-rays showed a dense $1.0 \times 2 \cdot 0$

Correspondence to Dr D. Mark, Eye Research Institute, 20 Staniford Street, Boston, Massachusetts 02114, USA. mm foreign body in the right orbit. B-scan ultrasonography revealed a magnetic foreign body in the mid vitreous of the right eye that left a trail of blood (Fig. 2). Our clinical diagnosis was bacterial endophthalmitis, right eye, complicating the presence of a magnetic intraocular foreign body. Conjunctival smears and cultures were obtained, and the patient was given methicillin $2 \mathrm{~g}$ intravenously, and gentamicin $80 \mathrm{mg}$ intramuscularly, preoperatively.

During the operation the foreign body was removed magnetically through the pars plana. Anterior chamber and vitreous smears and cultures were obtained, and gentamicin $200 \mu \mathrm{g}$ and methcillin $1 \mathrm{mg}$

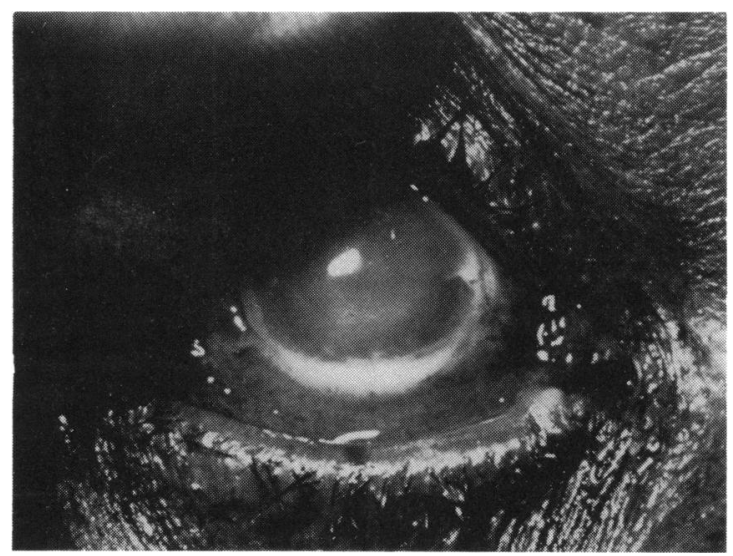

Fig. 1 Clinical appearance. Note entry site in the nasal cornea and hypopyon. 


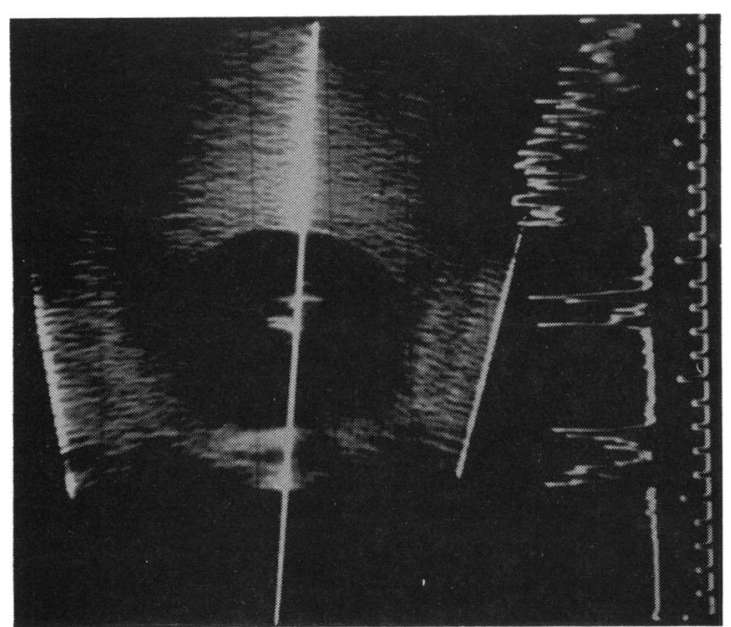

Fig. 2 B-scan examination shows metallic foreign body with a trail of blood in the vitreous.

were injected intravitreally. Subconjunctival gentamicin and methicillin and topical gentamicin were added to the systemic therapy of gentamicin 80 mg intravenously every 8 hours and methicillin $1 \mathrm{~g}$ intravenously every 6 hours.

There were Gram-negative coccobacilli on the vitreous smear and a few Gram-positive cocci in the anterior chamber. Initially the vitreous culture showed Gram-negative coccobacilli that were nonlactose fermenting and oxidase-negative. The organism was later identified as Acinetobacter anitratus from cultures of the anterior chamber, the vitreous, and the foreign body. The organism was sensitive in vitro to gentamicin, tobramycin, kanamycin, and amikacin; it was intermediately sensitive to carbenicillin and was resistant to penicillin. Conjunctival cultures showed a few diphtheroids in each eye.

By the second postoperative day the patient's condition deteriorated, and he had corneal infiltration and loss of light projection. Therefore the lens was removed intracapsularly and an open-sky vitrectomy was performed. This approach was necessitated by diminished corneal clarity. Repeated vitreous cultures were all eventually positive for Acinetobacter anitratus. Gentamicin $100 \mu \mathrm{g}$, which was given intravitreally at surgery, was given twice more over the following 4 days.

The patient improved and eventually developed a quiet eye with hand-movement vision, consistent with the degree of corneal opacification. The retina can be seen through a peripherally clear cornea and is attached with a normal-appearing posterior pole. Colour discrimination and 2-point discrimination are present.

\section{Discussion}

Acinetobacter calcoaceticus var. anitratus is a Gramnegative, nonfermentative, oxidase-negative bacterium that is ubiquitous in nature and for many years was considered infrequently pathogenic to man. However, in the past few years this organism has become an important cause of nosocomial infection and colonisation. $A$. anitratus has been reported to cause septicaemia, ${ }^{5}$ pneumonia, ${ }^{6}$ and meningitis ${ }^{7}$ in children and adults. A review of patients with infections due to this organism over a 2-year period at the Massachusetts General Hospital in Boston ${ }^{8}$ showed that $23 \%$ of 53 patients died of their infection. $A$. anitratus not only is an increasing nosocomial problem ${ }^{9}$ but also is being recognised as a community-acquired infection. ${ }^{10}$ Recent studies suggest that human skin may be an important reservoir of this organism, with up to $25 \%$ of persons having Acinetobacter sp. on their skin. ${ }^{11} 12$

Acinetobacter can cause a purulent conjunctivitis. Conjunctival smears may show Gram-negative intracellular diplococci resembling Neisseria, but the conjunctivitis is usually not as severe as when caused by that organism. Keratitis and corneal perforation can occur but rarely do. The conjunctivitis may be hyperacute and may be associated with urethritis. Keratoconjunctivitis clinically resembling keratitis sicca has also been reported. ${ }^{13}$

Two cases of serious ocular infection due to Acinetobacter lwoffi (formerly known as Mima polymorpha) have been reported. Chin ${ }^{1}$ reported a case of corneal perforation due to a mixed infection of Mima polymorpha and the fungus helminthosporium. The patient had a chronic corneal ulcer and had been treated with neosporin (neomycin sulphate, gramicidin, and polymyxin B sulphate) and topical steroids. Exactly which organism caused the perforation could not be determined. Wand et al. ${ }^{2}$ reported a case of hyperacute conjunctivitis in an 11-year-old girl who was lost to follow-up for 9 days and returned with a corneal perforation and iris prolapse. Because the smear. showed Gram-negative intracellular diplococci, the patient was treated with penicillin. Acinetobacter is resistant to penicillin, however, and the infection did not respond. The authors recommend that this type of conjunctivitis be treated initially with both penicillin and tetracycline.

Presley and $\mathrm{Hale}^{3}$ presented a case of a marginal corneal ulcer due to Bacterium anitratum. The ulcer was treated with chloramphenicol initially. The organism was then found to be resistant to chloramphenicol, and, after topical steroids were given, the cornea melted, requiring a conjunctival flap.

Peyman et al. ${ }^{4}$ reported a series of 20 cases of 
endophthalmitis in which Herellea sp. (now known as Acinetobacter anitratus) was the causative organism in one case. Phacoemulsification was the predisposing condition in this patient, who improved from light perception to $20 / 80$ vision after pars plana vitrectomy.

Our case of endophthalmitis is unusual in that the organism was presumably acquired outside the hospital environment. This strain of $A$. anitratus caused a severe and rapid inflammatory reaction in the eye that accelerated even after removal of the foreign body and intracameral antibiotic treatment. Fortunately the organism was sensitive to gentamicin.

The antibiotic susceptibilities of various strains of $A$. anitratus are unpredictable. Of extreme importance is the fact that many strains are resistant to the aminoglycoside antibiotics. At the Massachusetts General Hospital ${ }^{14} A$. anitratus has become the most frequently isolated Gram-negative species resistant to one or more of the aminoglycoside antibiotics. In particular only $46 \%$ of strains were susceptible to gentamicin. Virtually all of their clinical isolates were resistant to ampicillin, chloramphenicol, and the cephalosporins. Most strains were resistant to tetracycline as well. ${ }^{15}$ Other studies confirm these findings. ${ }^{610}$ Most strains appear to be susceptible to minocycline, doxycycline, and colistin.

\section{References}

1 Chin GN. Corneal perforation due to Helminthosporium and Mima polymorpha. Ann Ophthalmol 1978; 10: 607-9.

2 Wand M, Olive GM Jr, Mangiaracine AB. Corneal perforation and iris prolapse due to Mima polymorpha. Arch Ophthalmol 1975; 93: 239-41.

3 Presley GD, Hale LM. Corneal ulcer due to Bacterium anitratum. Am J Ophthalmol 1968; 65: 571-2.

4 Peyman GA, Raichand M, Bennett TO. Management of endophthalmitis with pars plana vitrectomy. $\mathrm{Br} J$ Ophthalmol $1980 ; 64: 472-5$.

5 Rocha H, Guze LB. Infections due to Bacterium anitratum. Arch Intern med 1957; 100: 272-5.

6 Cohen C, Forder AA, Ferguson AD. Pneumonia due to a resistant Acinetobacter organism. S Afr Med J 1981; 59: 387-9.

7 Green JD. Bacterium anitratum meningitis: report of a case and a review of the literature. Arch Intern Med 1960; 106: 870-3.

8 Glew RH, Moellering RC, Kunz LJ. Infections with Acinetobacter calcoaceticus (Herellea vaginicola): clinical and laboratory studies. Medicine 1977; 56: 79-97.

9 Ramphal R, Kluge RM. Acinetobacter calcoaceticus variety anitratus: an increasing nosocomial problem. Am J Med Sci 1979; 277: 57-66.

10 O'Connell CJ, Hamilton R. Gram-negative rod infections. II. Acinetobacter infections in general hospitals. NY State $\mathrm{J}$ Med 1981; 81: 750-53.

11 Buxton AE, Anderson RL, Werdegar D, Atlas E. Nosocomial respiratory tract infection and colonization with Acinetobacter calcoaceticus. Epidemiologic characteristics. Am J Med 1978; 65: 507-13.

12 Retailliau HF, Hightower AW, Dixon RE, Allen JR. From the Center for Disease Control. Acinetobacter calcoaceticus: a nosocomial pathogen with an unusual seasonal pattern. $J$ Infect Dis 1979; 139: 371-5.

13 Maudgal PC, Missotten L. Acinetobacter keratoconjunctivitis clinically resembling keratitis sicca. Bull Soc Belge Ophtalmol 1978; 182: 25-32.

14 Murray BE, Moellering RC. Aminoglycoside-modifying enzymes among clinical isolates of Acinetobacter calcoaceticus subsp. anitratus (Herellea vaginicola): explanation for high-level aminoglycoside resistance. Antimicrob Agents Chemother 1979; 15: 190-9.

15 Crues JV, Murray BE, Moellering RC. In vitro activity of three tetracycline antibiotics against Acinetobacter calcoaceticus subsp. anitratus. Antimicrob Agents Chemother 1979; 16: 690-2. 